\title{
The relationship between physical activity levels and symptoms of depression, anxiety and stress in individuals with alopecia Areata
}

\author{
Y. Rajoo ${ }^{1 *}$ (D) J. Wong ${ }^{1,2}$, G. Cooper ${ }^{2}$, I. S. Raj ${ }^{1}$, D. J. Castle ${ }^{3,4}$, A. H. Chong ${ }^{5}$, J. Green ${ }^{6}$ and G. A. Kennedy ${ }^{1,7}$
}

\begin{abstract}
Background: Alopecia Areata (AA) is an autoimmune condition that is characterised by non-scarring hair loss. Its aesthetic repercussions can lead to profound changes in psychological well-being. Although physical activity (PA) has been associated with better mental health outcomes in diverse populations, the association in individuals with AA has not been established. The aim of this study was to examine the associations between PA and mental health outcomes in individuals with AA to inform intervention strategies for this specific population.

Methods: A cross-sectional study was conducted among individuals who were diagnosed with AA. A total of 83 respondents aged (40.95 \pm 13.24 years) completed a self-report questionnaire consisting of International Physical Activity Questionnaire-Short Form (IPAQ-SF) and the Depression and Anxiety Stress Scale (DASS-21). Three-way contingency Chi-square analyses were used to determine the associations between PA, mental health outcomes and participants with hair loss of more than $50 \%$ on the scalp.

Results: $81.9 \%$ of the participants did not meet PA guidelines. Participants with hair loss of more than $50 \%$ on the scalp, and who did not meet PA guidelines, were significantly more likely to experience symptoms of severe depression ( $p=.003)$, moderate anxiety $(p=.04)$ and mild stress $(p=.003)$ than those who met guidelines

Conclusion: Findings suggest that increased PA participation in AA individuals with severe hair loss is associated with improved mental health status. Intervention efforts for this specific population should consider barriers and enablers to PA participation as they face challenges that differ from the general population.
\end{abstract}

Keywords: Alopecia areata, Depression, Anxiety, Stress, Physical activity

\section{Background}

In the general population, the prevalence of Alopecia Areata (AA) is estimated at $0.1-0.2 \%$ with a lifetime risk of $1.7 \%$ [1]. Mental health in individuals with AA has been studied [2] and findings suggest that individuals with AA experience high levels of anxiety, depression and stress in comparison with control populations [3, 4]. Gilhar and Kalis (2006) suggest that this could be due to the condition being characterised by the appearance of patches of non-scarring hair loss, which may occur in

\footnotetext{
* Correspondence: yamuna.rajoo@rmit.edu.au

${ }^{1}$ School of Health and Biomedical Sciences, RMIT University, Melbourne, Australia

Full list of author information is available at the end of the article
}

any hair-bearing region with a severity ranging from partial to complete hair loss on the scalp (alopecia totalis) and/or complete hair loss on the scalp and body (alopecia universalis) [5].

Although AA is not life-threatening, the aesthetic outcomes of this condition may affect mental health in these individuals [6]. One possibly debilitating characteristic of this condition is that it is associated with depression, anxiety [7] and stress [8]. A systematic review of epidemiology and burden of AA, examining worldwide incidence and prevalence of AA, indicated that individuals diagnosed with AA often consider their hair loss to be a serious problem, subsequently leading to distress and negatively impacting their quality of life and mental

(c) The Author(s). 2019 Open Access This article is distributed under the terms of the Creative Commons Attribution 4.0 International License (http://creativecommons.org/licenses/by/4.0/), which permits unrestricted use, distribution, and 
health [9]. The authors also found that treatment options for AA have limited success, and to date no cure has been found. Psychological support such as psychotherapy was also an important part of disease management, as AA can result in psychological burden [9].

Mental health constitutes a large social and economic burden for health care systems. For example, it is estimated around 8.5 million Australians, aged 16 to 85 years old, will experience a mental disorder, such as depression or anxiety in their lifetime [10] raising the question of effective and lasting treatments. Physical activity (PA) continues to gain the attention of practitioners and researchers with regard to its possible role prevention and treatment of different psychopathological abnormalities such as depressive symptoms [11]. Interventions that reduce the negative mental health symptoms may have important public health implications. The effects of conventional mental health therapies in people with AA such as psychotherapeutic treatments [12] has been investigated and reported. The study indicated that hypnotherapy may be effective for significantly improving and maintaining psychological well-being patients with AA. The possible role of PA either alone or as an adjunctive therapy in the treatment of mental health issues in people suffering from AA has not received any research attention research. Regular participation in PA plays an important role in maintaining mental health and its application has been shown to have positive effects [13]. For example, a study in an adult population involving 8098 participants from the United States compared the prevalence of mental disorders among those who did and did not report regular PA. The outcome indicated that over one-half of adults reported regular PA (60.3\%), which was associated with a significantly decreased prevalence of current major depression and anxiety disorders [14].

Studies have also shown the mental health benefits of participation in PA in other clinical populations such as those with chronic heart failure [15], cancer [16] and women with polycystic ovary syndrome [17]. In healthy populations PA is prescribed to optimise mental health conditions and high levels of physical activity are associated with quality of life and general vitality (a general measure of energy and fatigue) [18]. Similarly, these improvements are also observed in people with chronic health conditions [16].

Experiencing AA is psychologically challenging, causing intense emotional suffering which eventually leads to personal, social, and work related problems [19]. It strikes at a critical developmental period when young people are transitioning into early adulthood, with a mean age of onset reported between 25.2 [1] and 36.3 [20]. Hair is often considered as part of an individual's identity. Femininity, sexuality, attractiveness, and personality are symbolically linked to a woman's hair, more so than for a man [19]. Hair loss effects self-esteem and may lead to being targeted for ridicule and bullying. Some are very resilient, but most will struggle coping with AA [19], and therefore mental health management via PA may lessen these burden among these individuals.

To date, the associations between PA and mental health in individuals with AA have not been investigated. The aim of this study was to examine the association between levels of PA and scores on measures of anxiety, depression and stress (indicators of mental health) in Australian people suffering AA. Understanding the association between increased physical activity levels and improved mental health in people with AA may lead to important new PA based interventions that can be used in this population.

\section{Methods}

\section{Participants and study design}

This study was conducted in Australia using a cross-sectional approach to provide quantitative data on associations between PA and mental health in participants diagnosed with AA. A total of 83 participants responded to the study through the Australia Alopecia Areata Foundation (AAAF) network and the foundation's social media sites (i.e., Facebook Page, Website), and via word of mouth and collaborators' private practices. The inclusion criteria were: (1) aged 18 years and above; (2) diagnosed with AA by clinicians; and (3) not diagnosed with a serious active or uncontrolled disease that requires medical treatment (e.g., chronic obstructive pulmonary disease (COPD) or cardiovascular disease (CVD) that limits PA participation. The study protocols were approved by the Human Research Ethics Committee of RMIT (Royal Melbourne Institute of Technology) University, Australia in accordance with the National Health and Medical Research Council's guidelines (Approval reference: 59/14[19131]). Participants were given detailed information about the study aims, objectives and procedures. Informed consent was implied by the completion and return of the anonymous online or hardcopy questionnaire. Participation was completely voluntary, and participants could withdraw from the study at any time.

\section{Questionnaire}

The self-administered questionnaire elicited information about demographic characteristics (age, self-rated health status, education levels and annual income), AA status, severity and relapse of the condition. Characteristics of the disease such as duration, onset and recent treatments were also recorded.

\section{Assessment of physical activity}

The International Physical Activity Questionnaire- Short Form (IPAQ-SF) was used to assess the physical activity 
levels in individuals with AA. The IPAQ, designed to be used by adults ages 18 to 65 years old, has demonstrated reliability and validity against other self-report PA instruments (Spearman's $\rho$ 0.8, 0.3 respectively) [21]. Participants reported the frequency and duration of: (1) vigorous (examples given included heavy lifting, fast bicycling); (2) moderate (carrying light loads and bicycling at a regular pace); and (3) walking activities, as well as the average time spent sitting on a weekday, including sitting at work, during the last seven days [21]. Total moderate to vigorous physical activity (MVPA) in $\mathrm{min} /$ day was calculated by combining the activity score of both moderate and vigorous intensity activity for each work and recreational activity domain. Responses were converted to Metabolic Equivalent Task minutes per week (MET-min/week) according to the IPAQ scoring protocol. Participants were divided into two categories representing 'meeting' or 'not meeting' guidelines, based on the criterion of achieving at least 600 MET-minutes/ week $(150 \mathrm{~min})$ or more of at least moderate-intensity PA per week. This was derived from the Australian 2014 physical activity and sedentary behaviour guidelines for adult aged 18 to 64 [22].

\section{Assessment of depression, anxiety and stress symptoms}

Mental health status of the participants was assessed using the Depression and Anxiety Stress Scale (DASS 21) questionnaire [23]. The DASS21 questionnaire measures three dimensions of mental health; Depression (DASS21-D), Anxiety (DASS21-A), and Stress (DASS21S). The essential function of the DASS 21 is to assess the severity of the core symptoms of Depression, Anxiety and Stress. Each subset comprises of 7 items with responses reflecting four severity levels: (1) did not apply to me at all; (2) applied to me to some degree; (3) applied to me to a considerable degree; and (4) applied to me very much. To yield equivalent scores to the full DASS 42, the total score of each scale was multiplied by two and scores ranged from 0 to 42. Cronbach's alpha for the 21 item DASS questionnaire was 0.95 . The three scales were categorised into mild, moderate, severe, and extremely severe using the cut off scores from the Manual for the Depression Anxiety Stress Scales [23] allowing scores to be classified as symptomatic or symptomatic [24].

\section{Statistical analyses}

Statistical analyses were carried out using the SPSS software (IBM Statistical Package for the Social Sciences) program for windows version 24. Descriptive statistics were expressed as means $( \pm S D)$, frequencies and percentages. Three-way contingency Chi-square analyses were used to determine the associations between physical activity and mental health in individuals with AA experiencing hair loss. A $p$ value $<.05$ was used to evaluate statistical significance. The Cramer's V strength test was used to measure the strength of association of the Chi-square analyses. A post-hoc power analysis was conducted using the software package, GPower.

\section{Results \\ Sociodemographic}

A total of 83 participants, with a mean age of $40.95 \pm$ 13.24 years participated in the study. Table 1 shows the socio demographic characteristics of participants. Almost half $(49.2 \%)$ of the participants reported having body mass index (BMI) in the normal range. The proportion of participants who obtained at least a bachelor's degree, graduate diploma or postgraduate degree was 45.9\%). $75.4 \%$ of the participants originated from

Table 1 Demographic and socio demographic characteristics of Alopecia Areata $(A A)$ participants $(N=83)$

\begin{tabular}{|c|c|c|}
\hline Characteristics of participants & $\mathrm{n}=83$ & Percentage (\%) \\
\hline \multicolumn{3}{|l|}{ Age (years) } \\
\hline $18-24$ & 7 & 11.5 \\
\hline $25-44$ & 29 & 47.5 \\
\hline $45-64$ & 22 & 36.1 \\
\hline$>64$ & 3 & 4.9 \\
\hline \multicolumn{3}{|l|}{ BMI (Body Mass Index; kg/m²) } \\
\hline Underweight (<18.50) & 11 & 18.0 \\
\hline Normal (18.50-24.99) & 30 & 49.2 \\
\hline Overweight ( $\geq 25.00$ ) & 17 & 27.9 \\
\hline Obese $(\geq 30.00)$ & 3 & 4.9 \\
\hline \multicolumn{3}{|l|}{ Education attainment } \\
\hline Year 10 or equivalent & 8 & 13.1 \\
\hline Year 12/ trade certificate/diploma & 25 & 40.9 \\
\hline $\begin{array}{l}\text { Bachelor degree/Graduate } \\
\text { diploma/Postgraduate }\end{array}$ & 28 & 46.0 \\
\hline \multicolumn{3}{|l|}{ Annual Income (AUD) } \\
\hline$<40,000$ per annum & 18 & 30.5 \\
\hline $40,001-\$ 80,000$ per annum & 26 & 44.1 \\
\hline$>80,001$ per annum & 15 & 25.4 \\
\hline \multicolumn{3}{|l|}{ Country of origin } \\
\hline Australia & 46 & 75.4 \\
\hline Others & 15 & 24.6 \\
\hline \multicolumn{3}{|l|}{ Self-rated health } \\
\hline Fair/Good & 36 & 57.1 \\
\hline Very good/Excellent & 37 & 42.9 \\
\hline \multicolumn{3}{|l|}{ Smoking Status } \\
\hline Smoker & 6 & 8.1 \\
\hline Non-smoker & 57 & 77.0 \\
\hline Ex-smoker & 11 & 14.9 \\
\hline
\end{tabular}


Australia, while the rest came from New Zealand, USA, Canada, and non-English speaking countries in Europe, the Middle East and Asia. Almost half (49.3\%;) of the participants reported their self-rated health as fair or good, while the rest reported their health as very good or excellent.

\section{Epidemiology of AA}

All participants were diagnosed with a least one form of AA, however only $56.6 \%(95 \% \mathrm{CI}=45.3-67.5 \%)$ of the participants reported a specific form of AA. Alopecia Universalis was predominant among the participants with $52.8 \%$ (95\% $\mathrm{CI}=38.6-66.7 \%)$ of those reporting the specific form of AA, followed by Patchy Alopecia (37.7\%; 95\% CI $=24.8-52.1 \%)$ and Alopecia Totalis (9.4\%; 95\% CI $=3.1 \%-20.6)$. The scalp was the most common site of involvement, with or without involvement of other body sites such as the eyebrows, eyelashes, and pubic area. Around half (49.4 95\% CI $=38.2-60.0 \%)$ of the participants experienced hair loss affecting more than half the scalp (50\% and above). Hair loss affecting eyebrows, eyelashes and pubic areas were reported by $56.6 \% \quad(95 \% \quad \mathrm{CI}=45.3-67.5 \%), \quad 44.6 \% \quad(95 \% \quad \mathrm{CI}=33.7-$ $55.9 \%)$, and $47.0 \%(95 \% \mathrm{CI}=35.9-58.3 \%)$, respectively.

\section{Depression, anxiety and stress scale (DASS 21)}

As shown in Tables 2, 3 and 4, the severities for each dimension of mental health were categorised as normal, mild, moderate, severe and extremely severe. Participants with normal severity for all scales were considered asymptomatic, while mild, moderate, severe and extremely severe were considered as symptomatic [24]. All participants were considered symptomatic for anxiety and depression, but $8.4 \%(95 \% \mathrm{CI}=3.4-16.6 \%)$ of participants had normal levels of stress and therefore were considered as asymptomatic. More than half of the participants $(66.3 \%$; 95\% CI $=55.1-76.3 \%)$ reported extremely severe anxiety and a slightly lower percentage reported being extremely depressed $(47.0 \% ; 95 \% \mathrm{CI}=$ $36.0-58.3 \%$ ) and stressed (37.3\%; 95\% CI $=27.0-48.6 \%$ ).

\section{Physical activity (PA)}

The majority of the participants did not meet PA guidelines $(81.9 \%$; $95 \% \mathrm{CI}=72.0-89.5 \%)$. Middle aged adults (45-64 years) were significantly $(p=.02)$ more likely to meet PA guidelines (33.3\%; 95\% CI $=11.8-61.6 \%)$ than participants from all other age groups. Among participants who did not meet PA guidelines, adults aged 25 to 44 years old $(39.7 \%$; $95 \% \mathrm{CI}=28.0-52.3 \%)$ were significantly less likely $(p=.02)$ to participate in PA than other age groups. Body mass index (BMI) and forms of alopecia did not show any significant associations with PA.

\section{Association of physical activity, mental health and hair loss}

As only a fifth of the participants $(18.1 \%$; $95 \% \mathrm{CI}=10.5-$ 28.1\%) met PA guidelines, statistical inference did not reveal any association with mental health. Of those that did not meet PA guidelines, participants characterised with $50 \%$ and above scalp involvement experienced significant symptomatic depression $(p=.003)$ (Cramer's $\mathrm{V}=.414)$, anxiety $(p=.04)$ (Cramer's $\mathrm{V}=.308)$ and stress $(p=.003)($ Cramer's $\mathrm{V}=.414)$.

\section{Post-Hoc statistical power analysis}

The alpha level used for these analyses was $p<.05$. The post-hoc analyses revealed the statistical power for this study was .08 for detecting a small effect, whereas the power exceeded .90 for the detection of a moderate to large effect size. Thus, there was more than adequate power (i.e., power * .80) at the moderate to large effect size level, but less than adequate statistical power at the small effect size level.

\section{Discussion}

To our knowledge, this is the first study that has examined the associations between PA and mental health outcomes among Australian individuals with AA. The study results indicated that majority $(81.9 \%)$ of the participants did not meet recommended PA guidelines and all participants were symptomatic for anxiety and depression. In addition, scalp involvement (50\% and above) was a significant predictor for symptomatic depression, anxiety, stress and not meeting the recommended PA guidelines.

The findings from this study are in agreement with an earlier study conducted in 1991 where high rates of anxiety (39\%) and depression (39\%) were reported in a cohort of 31 individuals with AA in the United States [25]. Similar high trends of anxiety and depression were also observed in a study conducted in Iran, with a high

Table 2 Association between physical activity, depression and scalp involvement

\begin{tabular}{|c|c|c|c|c|c|c|c|c|c|c|c|}
\hline & \multirow[t]{3}{*}{ Variables } & \multicolumn{10}{|c|}{ DASS 21- Depression } \\
\hline & & \multicolumn{3}{|c|}{ Moderate } & \multicolumn{3}{|c|}{ Severe } & \multicolumn{3}{|c|}{ Extremely Severe } & \multirow[t]{2}{*}{$p$ value } \\
\hline & & $\bar{n}$ & $\%$ & $95 \% \mathrm{Cl}$ & $\bar{n}$ & $\%$ & $95 \% \mathrm{Cl}$ & $\bar{n}$ & $\%$ & $95 \% \mathrm{Cl}$ & \\
\hline Meeting PA guidelines & Scalp involvement (50\% and above) & 1 & 3.2 & $0.0-16.2$ & 0 & 0 & $0.0-26.5$ & 5 & 12.8 & $4.3-27.4$ & .06 \\
\hline Not meeting PA guidelines & Scalp involvement (50\% and above) & 17 & 53.1 & $34.7-70.9$ & 9 & 75.0 & $42.8-94.5$ & 9 & 23.1 & $11.1-39.3$ & $.003^{*}$ \\
\hline
\end{tabular}

*Significant association $(p<.05)$ 
Table 3 Association between physical activity, anxiety and scalp involvement

\begin{tabular}{|c|c|c|c|c|c|c|c|c|c|c|c|}
\hline & \multirow[t]{3}{*}{ Variables } & \multicolumn{10}{|c|}{ DASS 21-Anxiety } \\
\hline & & \multicolumn{3}{|c|}{ Moderate } & \multicolumn{3}{|c|}{ Severe } & \multicolumn{3}{|c|}{ Extremely Severe } & \multirow[t]{2}{*}{$p$ value } \\
\hline & & $\mathrm{n}$ & $\%$ & $95 \% \mathrm{Cl}$ & $\mathrm{n}$ & $\%$ & $95 \% \mathrm{Cl}$ & $\mathrm{n}$ & $\%$ & $95 \% \mathrm{Cl}$ & \\
\hline Meeting PA guidelines & Scalp involvement ( $50 \%$ and above) & 1 & 12.5 & $0.3-52.7$ & 0 & 0.0 & $0.0-16.8$ & 5 & 9.1 & $3.0-20.0$ & .16 \\
\hline Not meeting PA guidelines & Scalp involvement ( $50 \%$ and above) & 6 & 75.0 & $35.0-96.8$ & 11 & 55.0 & $31.5-77.0$ & 18 & 32.7 & $20.7-46.7$ & $.04^{*}$ \\
\hline
\end{tabular}

*Significant association $(p<.05)$

percentage of participants suffering from anxiety $(47 \%)$ and depression (56\%) respectively [26].

A study in Brazil indicated that hair loss was a common complaint among 157 women with AA and it was associated with a high prevalence of depression (29\%) [27]. In another study conducted among 3568 individuals with AA at tertiary care hospitals in Boston, United States indicated that during an 11-year period, mental health conditions such as depression or anxiety were found to be as high as $25.5 \%$ [3].

Individuals with minimal hair loss are able to cover the loss with remaining hair and are less likely to experience depression, anxiety and stress [19]. In a qualitative study conducted in the United Kingdom, individuals with AA indicated that hair loss was viewed as a negative attribute and reported the experience of stigmatisation, including being stared at, and receiving comments that hair loss was a sign of illness [28]. Wearing a wig to conceal hair loss has a positive impact on mental health status, but managing the noticeability of wigs can to lead to significant negative interpersonal consequences, including avoidance of social situations and exercise [28]. The participants further explained that wearing a wig also led to reduced activity, in particular sports activity, was avoided due to concerns about having to take off the wig or it falling off.

The IPAQ-SF was used in this study to measure the total PA. This scale has been recommended for population based studies due to its ease of administration, but it may tend to overestimate PA due to the lack of sufficient information about specific domains [29]. Nevertheless, the proportion of participants who did not meet PA guidelines $(81.9 \%)$ in the current study was much higher than that in the general Australian population (52\%; ABS, 2016). One reason for the low PA levels among participants in the current study could be that some participants wear a wig to conceal hair loss, which may lead to reduced activity, particularly sports activity [28]. Interventions in the form of PA in individuals with AA to improve mental health conditions have not been reported before. However, a study conducted in the United States found that individuals with AA were motivated to seek an alternative coping strategy such as PA due to their dissatisfaction with their current medical treatments. More than half of the respondents pursued exercise, while others tried yoga and other relaxation techniques (50.4\%) [30]. However, the outcome of the utilisation of PA was not reported in the study cited above.

Over the past two decades the literature in PA and mental health has been rising, but it appears that the positive outcomes have not been well utilised by health practitioners [31] as a management strategy. However, a study on willingness of psychologist to promote PA as psychological management, which involved 236 psychologist revealed that $83 \%$ reported often recommending PA, $67 \%$ often provided PA advice, and $28 \%$ often did PA counseling [32]. This study indicated that there was a high level of PA recommendation as part of mental health management among psychologists despite having minimal formal training in exercise promotion [32] .

Several studies have shown that PA had a positive impact on mental health in the Australian population [13], suggesting that it is feasible intervention for people with AA. The effects of PA are similar to those of psychotherapy and are apparent in a relatively short period of time

Table 4 Association between physical activity, stress and scalp involvement

\begin{tabular}{|c|c|c|c|c|c|c|c|c|c|c|c|c|c|c|c|c|c|}
\hline & \multirow[t]{3}{*}{ Variables } & \multicolumn{16}{|c|}{ DASS 21- Stress } \\
\hline & & \multicolumn{3}{|c|}{ Normal } & \multicolumn{3}{|c|}{ Mild } & \multicolumn{3}{|c|}{ Moderate } & \multicolumn{3}{|c|}{ Severe } & \multicolumn{3}{|c|}{$\begin{array}{l}\text { Extremely } \\
\text { Severe }\end{array}$} & \multirow[t]{2}{*}{$\begin{array}{l}P \\
\text { value }\end{array}$} \\
\hline & & $\bar{n}$ & $\%$ & $95 \% \mathrm{Cl}$ & $\bar{n}$ & $\%$ & $95 \% \mathrm{Cl}$ & $\bar{n}$ & $\%$ & $95 \% \mathrm{Cl}$ & $\bar{n}$ & $\%$ & $95 \% \mathrm{Cl}$ & $\bar{n}$ & $\%$ & $\begin{array}{l}95 \% \\
\mathrm{Cl}\end{array}$ & \\
\hline $\begin{array}{l}\text { Meeting PA } \\
\text { guidelines }\end{array}$ & $\begin{array}{l}\text { Scalp involvement (50\% and } \\
\text { above) }\end{array}$ & 1 & 14.3 & $\begin{array}{l}3.6- \\
57.9\end{array}$ & 0 & 0.0 & $\begin{array}{l}0.0- \\
52.2\end{array}$ & 0 & 0.0 & $\begin{array}{l}0.0- \\
23.3\end{array}$ & 2 & 7.7 & $\begin{array}{l}1.0- \\
25.1\end{array}$ & 3 & 9.7 & $\begin{array}{l}2.0- \\
25.8\end{array}$ & .17 \\
\hline $\begin{array}{l}\text { Not meeting PA } \\
\text { guidelines }\end{array}$ & $\begin{array}{l}\text { Scalp involvement ( } 50 \% \text { and } \\
\text { above) }\end{array}$ & 5 & 71.4 & $\begin{array}{l}29.0- \\
96.3\end{array}$ & 4 & 80.0 & $\begin{array}{l}28.4- \\
99.5\end{array}$ & 5 & 35.7 & $\begin{array}{l}12.8- \\
64.9\end{array}$ & 15 & 57.7 & $\begin{array}{l}37.0- \\
76.7\end{array}$ & 6 & 19.4 & $\begin{array}{l}7.5- \\
37.5\end{array}$ & $.003^{*}$ \\
\hline
\end{tabular}

*Significant association $(p<.05)$ 
(4 to 8 weeks) [31]. However, other findings suggest that a one size fits all intervention may not be suitable for individuals with AA [33]. Preferences for PA, and perceived barriers vary widely across populations especially in AA where the hair loss noticeability plays an important role in determining PA participation [28].

PA has a high level of acceptability as a management among individuals experiencing mental health conditions [34]. To support the change and promotion of PA interventions for individuals with $\mathrm{AA}$, more research is needed to explore the interests of people with AA [35]. Individualised PA intervention should be implemented addressing the barriers and enablers to PA. Such personalised interventions have been successfully implemented in other clinical populations [33].

There are several limitations of the current study that should be noted. This was a pilot study, and gender of the participants was not recorded and thus gender effects could not be determined, and also the sample size was small, limiting the analysis of smaller subsets within the sample.

\section{Conclusion}

Based on the findings of this study, further studies examining the associations of quality of life, mental health and PA in larger samples of participants with AA are recommended. This could take the form of participatory action research where perceived barriers and enablers to PA can be examined to address the needs of individuals with AA specifically. For example, focus group discussions allow researchers to understand the specific preferences and experiences of this population. Such a design would also allow for a quantitative analysis of how preferences affect adherence and outcomes to PA-based mental health treatment and management.

\section{Abbreviations}

AA: Alopecia areata; AAAF: Australia Alopecia Areata Foundation; COPD: Chronic Obstructive Pulmonary Disease; CVD: Cardiovascular Disease; DASS-21: Depression and Anxiety Stress Scale; IPAQ-SF: International Physical Activity Questionnaire-Short Form; PA: Physical activity

\section{Acknowledgements \\ The authors would like to gratefully acknowledge the Australia Alopecia Areata Foundation (AAAF) for the grant that funded this project. We would also like to thank the president of AAAF, Chel Campbell for her assistance and advice. We also wish to express our sincere appreciation to AAAF members who volunteered to participate in the study.}

\section{Author's contributions}

YR, JW, GC, ISR, CSJ, CAH, JG and GK have equally contributed to study design, data collection, analysis and preparation of manuscript. All authors read and approved the final manuscript.

\section{Funding}

This study was funded by Australia Alopecia Areata Foundation (AAAF). AAAF had no role in study design, data collection and analysis, decision to publish, or preparation of the manuscript.

\section{Availability of data and materials}

Datasets generated and analysed during the current study are not publicly available due to ethics regulations but may be available from the corresponding author upon reasonable request.

\section{Ethics approval and consent to participate}

The study protocols were approved by the Human Research Ethics Committee of RMIT (Royal Melbourne Institute of Technology) University, Australia in accordance with the National Health and Medical Research Council's guidelines (Approval reference: 59/14[19131]). Participants were given detailed information about the study aims, objectives and procedures. Informed consent was implied by the completion and return of the anonymous online or hardcopy questionnaire. Participation was completely voluntary, and participants could withdraw from the study at any time.

\section{Consent for publication}

Not applicable.

\section{Competing interests}

The authors declare that they have no conflict of interest.

\section{Author details}

${ }^{1}$ School of Health and Biomedical Sciences, RMIT University, Melbourne, Australia. ${ }^{2}$ School of Education, RMIT University, Melbourne, Australia. ${ }^{3}$ Department of Psychological Sciences and Psychiatry, University of Melbourne, Melbourne, Victoria, Australia. ${ }^{4}$ Department of Psychiatry, St. Vincent's Mental Health, Melbourne, Victoria, Australia. ${ }^{5}$ Department of Medicine (Dermatology), St Vincent's Hospital Melbourne, Melbourne, Victoria, Australia. ${ }^{6}$ Western Dermatology, Melbourne, Victoria, Australia. ${ }^{7}$ Institute for Breathing and Sleep, Austin Hospital, Melbourne, Victoria, Australia.

Received: 15 November 2018 Accepted: 17 July 2019

Published online: 23 July 2019

\section{References}

1. Tan E, Tay YK, Goh CL, Chin GY. The pattern and profile of alopecia areata in Singapore--a study of 219 Asians. Int J Dermatol. 2002;41(11):748-53.

2. Rencz F, Gulacsi L, Pentek M, Wikonkal N, Baji P, Brodszky V. Alopecia areata and health-related quality of life: a systematic review and meta-analysis. $\mathrm{Br} J$ Dermatol. 2016:175(3):561-71.

3. Huang KP, Mullangi S, Guo Y, Qureshi AA. Autoimmune, atopic, and mental health comorbid conditions associated with alopecia areata in the United States. JAMA dermatology. 2013;149(7):789-94.

4. Ghanizadeh A, Ayoobzadehshirazi A. A review of psychiatric disorders comorbidities in patients with alopecia areata. International journal of trichology. 2014;6(1):2-4

5. Olsen EA, Hordinsky MK, Price VH, Roberts JL, Shapiro J, Canfield D, et al. Alopecia areata investigational assessment guidelines--part II. National Alopecia Areata Foundation. J Am Acad Dermatol. 2004;51(3):440-7.

6. Alfani S, Antinone V, Mozzetta A, Di Pietro C, Mazzanti C, Stella P, et al. Psychological status of patients with alopecia areata. Acta Derm Venereol. 2012;92(3):304-6.

7. Gilhar A, Kalish RS. Alopecia areata: a tissue specific autoimmune disease of the hair follicle. Autoimmun Rev. 2006;5(1):64-9.

8. Brajac I, Tkalcic M, Dragojevic DM, Gruber F. Roles of stress, stress perception and trait-anxiety in the onset and course of alopecia areata. J Dermatol. 2003;30(12):871-8.

9. Villasante Fricke AC, Miteva M. Epidemiology and burden of alopecia areata: a systematic review. Clin Cosmet Investig Dermatol. 2015;8:397-403.

10. AlHW. Mental Health 2018.

11. Busch AM, Ciccolo JT, Puspitasari AJ, Nosrat S, Whitworth JW, StultsKolehmainen MA. Preferences for exercise as a treatment for depression. Ment Health Phys Act. 2016;10:68-72.

12. Willemsen R, Haentjens P, Roseeuw D, Vanderlinden J. Hypnosis and alopecia areata: long-term beneficial effects on psychological well-being. Acta Derm Venereol. 2011;91(1):35-9.

13. Strohle A. Physical activity, exercise, depression and anxiety disorders. J Neural Transm (Vienna). 2009;116(6):777-84

14. Goodwin RD. Association between physical activity and mental disorders among adults in the United States. Prev Med. 2003;36(6):698-703. 
15. Izawa KP, Watanabe S, Oka K, Hiraki K, Morio Y, Kasahara Y, et al. Association between mental health and physical activity in patients with chronic heart failure. Disabil Rehabil. 2014;36(3):250-4.

16. Zhao G, Li C, Li J, Balluz LS. Physical activity, psychological distress, and receipt of mental healthcare services among cancer survivors. Journal of cancer survivorship : research and practice. 2013;7(1):131-9.

17. Banting LK, Gibson-Helm M, Polman R, Teede HJ, Stepto NK. Physical activity and mental health in women with polycystic ovary syndrome. BMC Womens Health. 2014;14(1):51.

18. Conte F, Banting L, Teede HJ, Stepto NK. Mental Health and Physical Activity in Women with Polycystic Ovary Syndrome: A Brief Review. Sports Medicine (Auckland, Nz). 2015;45(4):497-504.

19. Hunt MH. The psychological impact of alopecia. BMJ (Clinical research ed). 2005;331 (7522):951-3.

20. Mirzoyev SA, Schrum AG, Davis MDP, Torgerson RR. Lifetime incidence risk of alopecia areata estimated at $2.1 \%$ by Rochester epidemiology project, 1990-2009. The Journal of investigative dermatology. 2014;134(4):1141-2.

21. Craig CL, Marshall AL, Sjostrom M, Bauman AE, Booth ML, Ainsworth BE, et al. International physical activity questionnaire: 12-country reliability and validity. Med Sci Sports Exerc. 2003;35(8):1381-95.

22. AlHW. Insufficient Physical Activity. 2018. https://www.health.gov.au/ internet/main/publishing.nsf/Content/health-pubhlth-strateg-phys-actguidelines. Last accessed on $30^{\text {th }}$ June 2019.

23. Lovibond PF, Lovibond SH. The structure of negative emotional states: comparison of the depression anxiety stress scales (DASS) with the Beck depression and anxiety inventories. Behav Res Ther. 1995:33(3):335-43.

24. Rao S, Ramesh N. Depression, anxiety and stress levels in industrial workers: a pilot study in Bangalore. India Ind Psychiatry J. 2015;24(1):23-8.

25. Colon EA, Popkin MK, Callies AL, Dessert NJ, Hordinsky MK. Lifetime prevalence of psychiatric disorders in patients with alopecia areata. Compr Psychiatry. 1991;32(3):245-51.

26. Baghestani S, Zare S, Seddigh SH. Severity of depression and anxiety in patients with alopecia Areata in Bandar Abbas. Iran Dermatol Reports. 2015; 7(3):6063.

27. Schmitt JV, Ribeiro CF, Souza FH, Siqueira EB, Bebber FR. Hair loss perception and symptoms of depression in female outpatients attending a general dermatology clinic. An Bras Dermatol. 2012;87(3):412-7.

28. Montgomery K, White C, Thompson A. A mixed methods survey of social anxiety, anxiety, depression and wig use in alopecia. BMJ Open. 2017;7(4): e015468.

29. Kim Y, Park I, Kang M. Convergent validity of the international physical activity questionnaire (IPAQ): meta-analysis. Public Health Nutr. 2013;16(3): 440-52.

30. Hussain ST, Mostaghimi A, Barr PJ, Brown JR, Joyce C, Huang KP. Utilization of mental health resources and complementary and alternative therapies for alopecia Areata: a U.S. survey. International journal of trichology. 2017; 9(4):160-4.

31. Takacs J. Regular physical activity and mental health. The role of exercise in the prevention of, and intervention in depressive disorders. Psychiatria Hungarica : A Magyar Pszichiatriai Tarsasag tudomanyos folyoirata. 2014; 29(4):386-97.

32. Burton NW, Pakenham Kl, Brown WJ. Are psychologists willing and able to promote physical activity as part of psychological treatment? International journal of behavioral medicine. 2010;17(4):287-97.

33. Moore G. The role of exercise prescription in chronic disease. Br I Sports Med. 2004;38(1):6-7.

34. Richardson CR, Faulkner G, McDevitt J, Skrinar GS, Hutchinson DS, Piette JD. Integrating physical activity into mental health services for persons with serious mental illness. Psychiatric services (Washington, DC). 2005:56(3):324-31.

35. Khan A, Brown WJ, Burton NW. What physical activity contexts do adults with psychological distress prefer? J Sci Med Sport. 2013;16(5):417-21.

\section{Publisher's Note}

Springer Nature remains neutral with regard to jurisdictional claims in published maps and institutional affiliations.

Ready to submit your research? Choose BMC and benefit from:

- fast, convenient online submission

- thorough peer review by experienced researchers in your field

- rapid publication on acceptance

- support for research data, including large and complex data types

- gold Open Access which fosters wider collaboration and increased citations

- maximum visibility for your research: over $100 \mathrm{M}$ website views per year

At $\mathrm{BMC}$, research is always in progress.

Learn more biomedcentral.com/submissions 